Euskal ikerketen aldizkaria | Revue d'études basques |

Revista de estudios vascos | Basque studies review

$9 \mid 2004$

Numéro IX

\title{
Heziketa literarioaren kezka, Peñafloridatik Mogelera
}

Ur Apalategi

\section{OpenEdition \\ Journals}

Édition électronique

URL : http://journals.openedition.org/lapurdum/778

DOI : 10.4000/lapurdum.778

ISSN : 1965-0655

Éditeur

IKER

Édition imprimée

Date de publication : 1 novembre 2004

Pagination : $39-47$

ISBN : 2-68781-376-X

ISSN : $1273-3830$

Référence électronique

Ur Apalategi, « Heziketa literarioaren kezka, Peñafloridatik Mogelera », Lapurdum [Linean], 9 | 2004,

Sarean emana----an 01 mars 2009, kontsultatu 22 avril 2019. URL : http://journals.openedition.org/

lapurdum/778 ; DOI : 10.4000/lapurdum.778 


\title{
Heziketa literarioaren kezka, Peñafloridatik Mogelera
}

\author{
Ur APALATEGI \\ UPPA
}

XVIII. mendearen ezaugarri nagusietako bat bere didaktismoa da. Horrela, aro neoklasikoa eta aro aurre-erromantikoa zerbaitek bereizten baditu hori ez da kutsu didaktikoaren presentzia edo presentziarik eza. Izan ere, biek ala biek gordetzen baitute joera hori. Aro batetik bestera igarotzean aldatzen dena irakatsi nahi dena da -irakaspenaren edukia- eta, apika nabarmenago, irakaspenaren hartzailea. Hori da hemen frogatzen saiatuko garena hiru obra aztertuz eta erkatuz : Xabier Munibekoa Peñafloridako kontearen El borra cho burla do opera komikoa, Bizenta Mogelen Ipui onak eta azken honen osaba Juan Antonioren Peru Abarka ezaguna. Eman dudan hurrenkera -Peñaflorida lehenik, Bizenta ondoren eta Juan Antonio azkeniknahitara eman dut, nahiz ez dion ez hiru argitalpen hauen kronologiari jarraitzen ez eta beren autoreen adinari. Urrunago ulertuko da zergatik egin dudan aukera hori, baina jakin bedi oraindanik nire jardunaren funtsarekin zerikusi zuzena duela.

\section{1-Literaturaren sailkapen kategoria historikoen erabilgarritsaunaz.}

Lehen lehenik, erabili gogo ditudan kontzeptuen garbiketa egiten hasiko naiz. Bi hitz, hasteko, hain errexki -eta nolabaiteko nagikeria intelektualez- erabili ohi ditugun sailkapen kategoria historikoetaz, gorago aipatu ditudan neoklasizismoa eta aurre-erromantismoa, nire gogoetaren garapenean funtsezkoak izanen baitira.

Herri batetik bestera, tradizio unibertsitario batetik bestera, darabiltzagun kategoria historikoak desberdinak izaten dira. Adibide argigarri bat ematearren, Frantzian sinbolismo hitzaz izendatzen den literatur problematikari Espainian modernismo deritzote eta Alemanian erromantismo. Bistan da, tradizio nazional bakoitzak tokian tokiko bere berezitasuna eransten dio problematika partikatu edo enbor amankomunari eta erreferentzia gisa hartzen diren autoreak bertakoak izaten dira. Gurean, adibidez, beranta historiko nabarmenarekin, Lizardi eta Lauaxetak ordezkatuko lukete tradizio sinbolista. Bidenabar, hemen mugimendu poetiko eta estetiko horri kritiko zenbaitzuk eman dioten izena post-sinbolismoa da (sinbolismo, tematika eta eginmolde antzekoak erabili zituztelako, eta post, ausaz urte ainitzeko berantarekin ekin ziotelako direlako gai eta errekurtsoak erabiltzeari) ${ }^{1}$.

Bada, gauza berbera gertatzen da XVIII. mende bukaera inguruko kategoria historikoekin. Erromantismoa Alemanian hasten da XVIII. mendearen azken herenean eta guk sibolismo deritzogunerainoko korronteak besarkatzen ditu hitzak

1 - Guk dakigula, postsimbolismo terminoa, gerraurreko euskal poesia lirikoari aplikatuta, Jon Kortazarri zor zaio (cf. Literatura vasca, Siglo XX). 
tradizio germaniarrean. Frantzian, berriz, erromantismoa 1820 inguruan sortzen dela esan ohi da, Napoleonen hondamendiaren ostean. Aldiz, aurreerromantikotzat jo ohi dira Rousseau bezalako idazle zenbait, zeintzuek ageriko loturak baitituzte erromantismoa bihurtuko den "sentsibilitate berri » horrekiko : norbanakoaren kontzientzia zorrotz bezain mingarria, kasurako. Zergatik deitu beraz idazle hauek aurre-erromantikoak, eta zertan da berezia beraien jarduna ? Arrazoi askoren artean -eta ez naiz garai horren espezialista bat, ezta hurrik eman ere-, uste dut gizabanakoaren zorigaiztoa (edo zorigaizto sentipena) gizartearen hobekuntza baten bidez senda daitekeelako uste edo itxaropenari eusten diotelako direla ez arras/oraindik erromantiko. Itxaropen honen ondorioetarik bat aro neoklasikoarekiko lotura suposatzen duen beraien literaturaren kutsu didaktikoa da, dudarik gabe. Rousseau baten barne disposizioa erromantikoa izanik ere -hau da, betirako galdu den zerbaitek eragiten duen malenkoniarekin zerikusia badu ere-, hitzarmen soziala eta hezkuntza berritu baten gainean oinarrituriko "iraultza" -Emile eleberri famatuan garatzen duen eredua- proposatzen du zulotik ateratzeko edo gizakia bere onera itzultzeko. Zertan dira, beraz, galdetuko du batek, desberdinak aurre-erromantismoa eta aro neoklasikoa? Ez al dute, finean biek literatura didaktiko bat egiten gizakia hezkuntzaren bitartez hobetzeko ? Bada, hemen ere, bereizkuntza bat egitea komeni da. Gizartearen hobekuntza prozesu historikoan sinesten duten neoklasikoek Antzinate klasikoan aurkitzen dutelarik gizartea eta gizakia zuzentzeko inspirazioa -bai estetikoki, bai etikoki-, aurre-erromantikoentzat, ordea, gizarte zibilizatutik kanpo aurkitzen da jatortasuna. Jatortasuna gizakiaren eta historiaren jatorrian xekatu behar dira. Rousseaurentzat, jakina denez, gizakia gizarteratu aitzin ona zen eta gizarteratzeak zuen gaiztotu. Hortik naturara itzultzeko beharra eta izadiarekiko konfidantza. Hortik, baita ere, pedagogiaren berritze goitik beherakoa : haurrari ez zaizkio buruan irakaspenak sartu behar, haurraren natura edo izaeraren ezagutzatik abiatu behar da irakatsi nahi duena.

Orain arte esandakoa laburbiltzeko, neoklasikoek eredu klasikoetan oinarrituz hobetu nahi dituzte gizakia nahiz gizartea eta etorkizun gero eta hobean sinesten dute, aurre-erromantikoak gizakiaren baitan datzan primitibotasun galdu baten bila abiatzen dira eta bere baitako zer horren deskubritzea da hezkuntza prozesuaren oinarria. Erromantikoek ere iragan urrunean -klasikotasunetik at, Erdi-Aroan edota zibilizazio primitiboetan- bilatzen dute galdutako perfekzioa, baina hezkuntzarako kemenik gabe, dena galtzera doalakoan.

\section{2- Hezkuntza neoklasiko bat: El borracho burlado eta Ipui onak.}

Zehazten saiatu garen kategoria historiko orokorregi hauen baliagarritasuna frogatzeko -edo auzitan jartzeko-, adibide konkretuetara jo behar da orain. 1764ean, Azkoitiko zalduntxoen buru den Xabier Maria de Munibe e Idiakez izeneko Peñafloridako konteak El Borracho burlado opera-komikoa argitaratzen du. Zalduntxo ilustratuen historia apur bat ezagutzen duenak badaki zientzia eta, orohar, ezagutzarekiko zaletasuna aurkitzen dela beraien ekimen gehienen abiapuntuan, Bergarako mintegia izanen delarik zaletasun horren emaitzarik ikusgarriena. Zalduntxoen hastapenetako akademiaren jarraipen eta garapena bihurtuko den Herriaren Adiskideen Elkarteak du sortuko Bergarako mintegia eta elkartearen oinarriei behako bat ematea ez da alferrikakoa jarduera literarioa nola ikusten zuten ulertzeko.

Bere heriotzaren atarian (1785 inguruan), RSVAP-en estatutuen egile den Munibek elkartearen hastapenak gogora ekartzen ditu eta antzerkiaz honako gogoeta egiten du : 
El objeto de la Sociedad serían las ciencias, bellas artes y Artes y que para promoverlas con suceso serían necesarias anuales Asambleas para las cuales admitieron estos principios : 1) Que era precisa una honesta diversión para el tiempo en que se juntasen tantos caballeros en un lugar, 2) Que no se podía escojer otra más amena, ni más util, que la del teatro, 3) [...] 5) Que ocupando esta diversión las noches se dedicarían los días al cultibo de la ciencia, bellas letras y Artes ${ }^{2}$.

Antzertiari beldurra omen diote batzuek eta haientzako erantzuna prest du kondeak: "El nombre solo [de teatro], asustará a quien no haya reflexionado los varios medios por donde puede purificarse y hacerse ventajoso [... $]^{\prime \prime 3}$. Elkartearen sortzeak ez du iritzi publikoa sorgor utzi eta Peñafloridak honela kontatzen du gertatutakoa : "Unos pintaban este presentable cuerpo con los rasgos de dedicado a solo una profana diversión [hots, antzertira emana] otros lo miraban como escuela de ociosidad y aún de libertinage $[\ldots]^{4}$. Antzertiarekiko tirria berezia duen Munibek nola edo hala antzertiak eragiten duen beldurra uxatu nahi luke eta hori egiten ahaleginduko da Elkartearen aitzinean emanen duen "antzertiaren defentsan" izenburuko hitzaldiarekin ${ }^{5}$ :

Lamentase al principio de que reinasen estos inconvenientes en las personas sabias y destinadas a la instrucción de la verdad. Advirtió ser necesario este desengaño, para evitar la nota de nuestra nación, respeto a la cultibadas [...] [lamentose también que] hombres, que en otras materias discurren con juicio, solo parezcan atolondradas cuando se trata de teatro y se persuadió a que en unos, nacía de ignorar aún la definición de los espectáculos, las reglas de la Poesía Dramática, y las obras escogidas en este género. En otros de que por no haberlas visto ejecutar, como cosa incompatible a su profesión, no quieren que los demás, que dependen de su dirección, disfruten este entretenimiento. Y otras enfín habituadas a no admitir en su alma, otras impresiones que la de la melancolía, no pueden admitir objetos revestidos de algún placer. Todos juntos empeñados en impugnar el teatro, tratan a quién le defiende de impio, de Ateista, de hereje, de Hombre que no cree a los Santos Padres cuando aseguran que la comedia no se puede ver sin pecado $[\ldots]^{6}$.

Izan ere, aro neoklasikoaren helburu pedagogikoei hobekien egokitzen zaien generoa ez da bereziki ongi ikusia garai hartako Espainia oscurantistan. Ez dezagun ahantzi, gure egungo ikuspegitik arras paternalista iruditzen zaigun Zalduntxoen proiektu hezitzailea, garai hartako testuinguru espainiarrean arras aurrerakoia eta, hein batean, iraultzailea zela. Ilustrazioaren izpiritu berria zabal dezakeen orori beldurra dio Eliza boteretsuak, eta nola ez antzerkiari. Horren aitzinean, Peñafloridak antzertiari nolabaiteko bedeinkapena eman dieten hainbat autoritate moral (hots, katoliko) zerrendatzen ditu (Leon X, Richelieu, Fleury, St Thomas d'Aquin...). Bere oldar defentsiboa gelditu ezinik, Munibek, sermoiaren ordezko gisa proposatuko du antzertia, ohartua baita mezatara ez doazen horiexek direla antzerkiak ikustera joan ohi direnak.

Nolanahi den, Peñaflorida eta bere lagun zalduntxoak ez dira libertinoak ez eta iraultzaileak ere. Aurrerakuntzaz gain, ordena soziala dute helburu -beren klase pribilegioak babesteko- eta horren froga dugu honako esaldi hau : "un verdadero sabio siempre más sumiso cuanto más ilustrado, descansa sólo en la verdad, y

2 - Revista Internacional de Estudios Vascos, 21, 323.

3 - Ibid., p.325.

4 - Ibid. p.323.

5 - Goraxeago aipatu dugun testu autobiografiko horretan ematen du hitzaldi horre laburpena kondeak berak.

6 - RIEV, 22, 444. 
firmemente persuadido a la limitación de sus alcances venera las decisiones de la Iglesia" ${ }^{\prime 7}$. Bere asmoa xumeagoa da, eta finean, kontserbatzaileagoa; herri xumea hezi nahia ez datorkio kontzientzia sozial batetik, baizik eta herria modernizatzeko egin gogo duen erreforma ekonomiko eta moralari eraginkortasun handiagoa emateko kezkatik. Erreforma moralari dagokionez, antzertia hobesten du, sermoien gainetik. Horra bere ausardia. El Borracho Burlado obraren edizio kritikoa paratu duen Xabier Altzibarrek ongi dioen bezala, kondeak antzerti musikala hezkuntza tresna gisa proposatu zuen :

[...] badirudi Adiskideek teatroari buruz zuten adiera gizartea ikusteko modu bati zegokiola "dena herriarentzat, baina ez herriarekin" esamoldeak laburbiltzen duen despotismo ilustratuari alegia -honek aristokraziari "polizia" eginkizuna ematen baitzion hitzaren jatorrizko esanahian, hau da, antolamendu egokia eta berebat ohituren fintasuna babestea, El borracho burlado-ko protagonista den Txanton Garrote bezalakoen jokabidea aldaeraziz ${ }^{8}$.

Bere misioa bete ahal izateko, jakina, antzertia printzipio neoklasikoen galbahetik pasatu beharko da. Arau hauen berri Elkartekide den Felix María Samaniego alegia egile eta Peñafloridaren ahaideak ematen digu 1786ean argitaraturiko Carta sobre el tea tro testuan:

De tres objetos que pueden proponerse los que gobiernan su teatro, a saber enseñar, cultivar y entretener, por lo común se cuida sólo al último [...]. No basta que el teatro instruya, es menester también que pula y que cultive [...], que dé buenas máximas de educación y conducta, que enseñe a respetar las clases que componen un estado, que inspire a cada uno el amor a los deberes, que haga conocer cuánto valen en el uso del mundo el decoro, la cortesanía, la afabilidad, y haga apreciar la generosidad, el candor, la veracidad, la buena fe, el recato, el recogimiento, la aplicación al trabajo y otras mil vicisitudes civiles que por lo común tienen en poco los ignorantes y orgullosos?.

Literaturaren ikusmolde utilitarista da nagusi, beraz, Zalduntxoen artean, eta ez gaitu harrituko beraz, Munibek Horazioren maximaren babespean agertzea Elkartearen jarduera literarioak : “atseginaren bitartez hezi". Elkartearen 1766ko bilkura orokorrean zera adierazten du Peñafloridak :

[...] la Sociedad ha hecho un arreglamiento [comprendre : règlement] tan nimio para la ejecución de las piezas de teatro que no parece pueden añadirse precauciones a las que ella misma ha dispuesto. La pureza de las piezas es el fundamento, el hermoso y arreglado orden de ejecutarlo es el fruto, y la continua instancia y súplica que hace el Auditorio para que advierta lo que pide remedio es una prueba nada equívoca de su celo"10.

El Borracho Burlado, opera-komikoaren eredu paristarretatik zuzenean inspiratua $\mathrm{da}$, eta eredu horrek berak asko zor die opera-bouffe italiarrei ${ }^{11}$. Azken hauetan bezala kondeak istorioaren hari nagusia sinplifikatzera jo du, kokapen fantastikoak baztertuz eta egunerokotasuna hobetsiz bai apaindurei dagokienez bai pertsonaiak taxutzerako orduan. Ardoaz maiteminduriko gizon alfer baten eskarmentua ekarriko duen iruzurra baino gai egunerokoagorik badea, izan ere ? Eta zapatariak

7 - RIEV, 21, 320.

8 - X. Altzibar, Peñaflorida Kondearen El Borracho Burlado obraren edizio kritikoa, Euskal Parlamentua, Gasteiz, 1991, p.36.

9 - F.M. Samaniego, "Carta sobre el teatro", in Julián Apraiz, Obra s críticas de D.F.M.Samaniego, Cardenal, $1898,81-102$.

10 - RIEV, 21, 325.

11 - Donald Jay Grout, “Opéra bouffe et opéra-comique”, in Histoire de la musique 2, Ed. Pléiade, Paris, $1963,13$. 
bere denda daukan jaun baten etxearen behekaldea baino dekoratu arruntagorik? Intriga bera ere ezin sinpleagoa da : Don Diego etxeko jaunaren zerbitzariak mozkorragatik lokarturik gelditu den Txanton Garrote, azken honen emazte Maritxuren laguntzaz, aberaski janzten du sinestarazteko markes bat dela. Iratzartzen delarik, bai emazteak eta bai iruzurrean inplikatutakoek markestzat baleukate bezala jokatuko dute. Pixkanaka, Txantonen mesfidantza garaituko dute eta bere klase aldaketaz komentzitzea lortuko ere, azkenean iruzurra Don Diegok berak salatuko duen arte, berau ere noblez mozorroturik agertuko delarik eta Txantonengan urkatzearen mehatxuaz beldurra eraginez. Txantonek barkamena eskatuko dio bere emazte sakrifiktu eta langileari eta edateari eta alferkeriari bizkar emanen diela aginduko dio.

Bidenabar, ohargarria da nola bere xumetasunean, intriga honek dimentsio erreflexibo bat garatzen duen antzerkiaren barruko antzerkia antolatuz (Ha mlet-en bezala). Alegia, bere ohiko antzertiaren defentsa Peñafloridak oraingoan taula gainean eta fikzioaren bitartez gauzatzen duela : izan ere, Txanton Garroteren erreforma morala ikustera gonbidatzen bagaitu opera-komiko honek, erreforma hori istorio horren barruan pertsonaietako batek antolatzen duen trikimailu teatral baten bidez lortzen da. El borracho burlado-ren intriga mekanismo teatral neoklasikoaren mise en abyme bat bezala irakur daiteke hortaz. Txanton ez du sermoi batek erreformatuko, ezta arrazoi arrazionalak, baizik eta antzertiaren larderiak. Zigorraren beldurra eta erridikuloa paratzeak dakarrena dira Txantonen bizimodua norma sozial egokietara makurtuko dutenak, baina beldur horren eraginkortasuna bere jatorri teatraletik dator hemen, komedia barruko komedia -gai ezin barrokoagoa- da mundua ohitura gaiztoetatik libratuko duena. Eta Txanton Garrote antzerkiak erreformatzea lortu badu -ilusio teatralaren bitartez, eta funtsean gezurraren indarraz, zeren Txantonek ez baitu jakinen Don Diego zerbitzari mozorrotua dela bukaeran mehatxu egitera datorkion noble faltsua-, zergatik ez ote luke lortuko antzezkizunaren ikuslegoa ere erreformatzea ? Hori da Peñafloridaren ustea eta, honetan ere noeklasikoen antzera, Aristotelesen teoria katartikoa dago ustearen oinarrian :

Cómo es posible que una persona racional no abandone aquel vicio, aquella imperfección que le dominaba, después que la vé en el teatro objeto de la irrisión de todo el Pueblo ?Corrido y avergonzado, apenas se atreve a levantar los ojos del suelo, por no ver que el auditorio fija los suyos en él, como en objeto de la misma representación, y allí mismo saca por fruto hechar de sí lo que ha visto ridiculizado ${ }^{12}$.

Ikuskizunaren kontzepzio hau, Jon Juaristik ongi zioen bezala, despotismo ilustratuaren dogmekin bat dator: "la nobleza debe tomar a su cargo la educación moral y la vigilancia de costumbres de un pueblo demasiado ignorante y simple para poder regirse por sí mismo"13. Gorago esan dugunez, herriarentzat egina da antzerti neoklasiko hau, baina herria transformakuntza moralaren objektu pasiboa izatera mugatzen da. Datu esanguratsua da, alde horretatik, obraren lehen emanaldian -sortzeko zorian zegoen Elkarteko kideak biltzeko eman zen obra Azkoitian 1764eko uztailaren 7an- oholtza gainean antzezle izan zirela Peñaflorida, Narrosko markesa eta Samaniego idazlea. Pentsa daiteke antzeztokian herritar xume gutxi izan zela eta gehientsuenak aitonen seme, elizgizon ala burgesak izan zirela. Bestalde, paradoxa barroko baten ondorioz apika, obraren lehen atzezle horiek 
nobleak baziren, interpretatzen zituzten pertsonaiak noblez mozorroturiko herritarrak ziren. Hitz batean esateko, herria hezi nahi da, baina bere presentziarik ez dago ez taula gainean ezta ikuslegoan ere. Kontzientzia txarrik gabeko klasismoaren garaiean aurkitzen gara, dudarik gabe.

Beste hainbeste esan daiteke Bizenta Mogelek bere alegia sortarekin XIX. mendearen hasieran gauzatuko duen xede literarioaz. Kronologikoki mende berrian kokaturik egon arren, liburu hau eta berau bermatzen duen poetika guztiz dira XVIII. mendekoak, eta konkretuagoki, aro neoklasikokoak. Neoklasizismo berankor baten azken emaitzaz mintza gaitezke kasu honetan. Samaniegok bezala proiektu literario neoklasikoari ezin hobeto egokitzen zaion alegiaren generoa landuko du Mogel gazteak. Jakina da alegia beti bi zatiz osatzen dela eta bigarren zatiak -ondorioak edo moralak- lehenaren izaera entretenigarria nolabait konpentsatu egiten duela, kutsu didaktikoa eta moralizatzailea emanez osotasunari.

Liburuaren azpi-tituluan nahiz aitzin-solasean Bizenta Mogelek ederki asko sintetizatzen du xede literario horren helburua eta bertan ematen den irakaspenaren destinatarioa. Ipui on izendatu baditu alegia hauek ipui "oker eta zatarrei" kontrajarriz dagi hori. Delako ipui okerrak berak bere gaztaroan dastatu dituen irakaspenik gabeko ipuin arinak - "farragarri eta sustrai gabeak"14 - dira. Eta batez ere, hau esplizituki aitortzen ez bada ere, ipuin herrikoiak dira, hau da, elite sozial ilustratuaren kontrolpean ez dauden edukiak garraia ditzaketenak.

Bestalde, esaten zaigu ipuin hauetan "euskaldun nekazari eta gazte guziak" erakaste ederrak aurkituko dituztela beren bizitza zuzentzeko ${ }^{15}$. Peãfloridarekin gertatzen zenez, klase sozial ilustratuak bere bokazio pedagogikoa mandatutzat dauka eta ez zaio inoiz burutik pasatuko bere partaideak ere hezigarriak direnik edota besteengandik zerbait ikasi dezaketela. Kontzientzia onarekin jarraitzen dugu. Aipagarria suertatzen da, baita ere, nekazaria eta haurra parekatzean azaleratzen den paternalismo inkonzientea. Hemen, halere, aldaketa txiki bat nabari da Peñafloridaren garaiarekiko. Hezi nahi dena ez da edozein herritar, baizik eta nekazaria. Horra behar bada, Bizentak aurre-erromantismoari zor dion gauza bakarra.

Izan ere, Bizentak bere alegia bilduma Peñaflorida kontearen bilobari eskaintzen dio -familia (onen) arteko kontuak dira garai hartako ilustratuen literatur ekintza hauek eta entzutekoa da eskaintza orri nahiz aitzinsolasetan elkarri egiten dizkieten losintxak- eta deigarria da eskaintza testuaren osagai bat. Behin eta berriro azpimarratzen du Bizentak Munibetarren laborariekiko txera. Hona bi adibide :

Nekazari baten semetxo bati egingo diozu zuk agur ain gozoa, nola errege batenari, ta orobat da zuretzat abarkadun mutiltxoa nola, zapata bitxituz estalia ${ }^{16}$.

Ezagutu zutenak izen oneko zure aita-aita jaun D. Xabier Maria Munibe ta Idiakez, ez daukate azturik bere lautasuna nekazari guzientzat ; nola ematen zioen eskua estu estu ta lastantasunez baserritarrai ${ }^{17}$.

Nekazari laborari edo baserritarraren figuraren agerpena iraultza intelektual aurre-erromantikoari zor zaio dudarik gabe. Rousseaurekin hasi eta Herderrekin jarraituz, naturaranzko edo primitibotasuneranzko itzultze prozesu horretan nekazariaren figura birdeskubritzen da Europa osoan XVIII. mendearen azken

14 - Bizenta Mogel, Ipui onak, Euskal editoreen elkartea, 1990, 28.

15 - Ibid., 33. or.

16 - Ibid., 23. or.

17 - Ibid., 24. or. 
herenean. Zergatik eman halako tokia laborariari ? Bada, bera delako, intelektual aurre-erromantikoentzat, naturatik edo giza kondizio primitibo kutsatu gabetik hurbilen gelditu den gizakia, zibilizazio hiritar endekatuak usteldu ez duen bakarra, egiazko kultura -herrikoia eta ez goi klase kosmopolitena-, beraz kultura nazionalaren esentzia atxiki duena.

Alabaina, Bizenta Mogelek ez du logika aurre-erromantikoa bururaino eramaten eta nekazariari txera berezia erakusten badio jarraitzen du hezkuntza morala goitik beherako prozesu sozial gisa ikusten. Irakaspenaren edukiari bagagozkio ere guztiz neoklasikoa da bere planteamentua ez baitu aurre-erromantikoek egingo duten modura dudatan jartzen tradizio klasikotik jarauntsiz eta behin betiko jasotako ondare morala. Aldaketa aurre-erromantiko horiek guztiak bere osabak eramango ditu aurrera, Juan Antonio zaharrak, alemandar filologoekin kontaktuan izandako Mogel zaharrenak, Peru Abarka zahartzaroan idatziriko obraren bitartez.

\section{3-Hezkuntza aurre-erromantiko bat: Peru Abarka.}

Gure literaturaren aurre-historiara joz gero -aurre-historia deritzot kontzientzia literarioaren agerpena baino lehen idatzitako testuei ${ }^{18}-$, hain ardura (ia beti) gertatzen denez, hitzaurreak testuak bezain aberats eta interesgarriak dira. Oraingoan ere luzaz lotuko gatzaizkio Peru Abarka-ren paratestua aztertzeari.

Maiz aipatu da Mogelen proto-eleberriak euskarari (bizkaierari baita euskarazko eleberrigintzari) egindako ekarpena. Gutxiagotan aztertu da, behar bada, bere ekarpen filosofiko-ideologikoa eta arlo honetan egiten duen iraultza erabatekoa. Gure XXI. mendeko talaiatik, noski ezin atzerakoiagoa iruditzen zaigu Peru baserritarrak Maisu Juan hiritar endekatuarekin daukan elkarrizketan zehar orrialdez orrialde defenditzen duen tradizionalismoa sozial zein moral nahiz linguistikoa. Bada, eta hemen harreraren teoriaren eta berezikiago Jauss-en igurikimen zerumugaren kontzeptua lagungarri zaigu zinez, behar-beharrezkoa da obra bere garaieko irakurleriaren igurikimen literario nahiz ideologikoen arabera epaitzea. Zeren, eta hori frogatzen ahaleginduko naiz, Peru Abarkaren -pertsonaiaren edo obraren, ala bien- tradizionalismoa iraultzailea baita erebat.

Has gaitezen espazio kontu batzuekin, bisualki ere ageri baita sentsibilitate aldaketa Peñafloridaren edo Bizentaren obretatik Mogel osabarenera.

El borracho burlado-ren didaskaliei begiratuz gero, eta konkretuagoki pertsonaien aurkezpen-zerrenda egiten den orriari erreparatuz gero, ohartuko gara autoreak zera dioela bere istorioaren kokapen espazialaz: "La scena es la casa de un caballero, en cuyo suelo bajo tiene el zapatero su tienda"19. Beraz, Txanton "hombre ordinario" -aren hezkuntza prozesua aitoren seme baten etxean garatuko da. Are, iruzur teatral hezitzailea gauzatu ahal izateko Txanton lo dagoela zapatariaren solairutik zaldunaren solairura eramango dute. Hots, noblearen solairuan eta noblez nahigabe mozorroturik aurkituko delako ikasiko du nagikeria eta hordikeria baztertu behar dituela bere bizitzatik.

18 - Salbuespenak salbuespen -Oihenart bakarra izatea baliteke- kontzientzia literarioaren agerpena XX. mendearen lehen herenean kokatzen dut, Lauaxeta Lizardi binomioarekin. Kontuan harturik bi adar dituela kontzientzia literarioa deitzen diodan horrek, hau da, batetik idazlea bera literatura egiten ari dela ohartzea eta hori izatea helburu nagusi eta, bestetik, euskal tradizio literario baten ezagutza minimo batetik abiatuta idaztea. Jakina, bi baldintza hauek betetzen direnerako ia berez betetzen da hirugarrena, hots, erakunde literario baten agerpena hitzaren zentzu konkretu nahiz abstraktuan (literatura kezka nagusi duen mikrokosmo baten eraketa).

19 - Munibe, op.cit., 208. 
Har dezagun orain Peru Abarkaren hari diegetiko mehea. Hemen hezitokia ez da aitoren seme baten jauregia baizik eta laborari baten etxaldea. Eta heziketaren destinatarioa ez da arestiko hombre ordina rio-delakoa baizik eta hiritar atxeter ikasi eta titulatua. Irakaslea, bestalde, denok dakigunez, baserritarra bera da, izenburuaren azpi-tituluak modu umoristikoan "catedrático de la lengua bascongada en la universidad de Basarte" izendatzen duen Peru Abarka. Ez dakigu kasualitate hutsa den, baina guri hemen ezin hobeto datorkigu, obra aurreerromantiko honetan ere, opera-komiko neoklasiko hartan bezala, mozorroketa bati esker gertatzen da heziketa horren "ikaslearen" kontzientzia hartzea, kasu honetan Maisu Juanena. Sinbolismoa gardena da : zortez Peruk bere baserritar jantziak prestatu dizkiolako bakarrik salbatzen da Maisu Juan presondegiratze ziur batetik (liburuaren lehen kapituluan ostatu batetik ordaindu gabe eta jabea zauriturik alde egin ostean). Autoritatearen ordezkariak alde egin bezain laster, eta baserritarraren jantziagatik libratu dela ulerturik, Maisu Juanek Peruri adierazten dio bere irakaspenak ontzat hartzen dituela eta bere aurreko usteei uko egiten diela.

Hemen beraz, literaturak ez du galdu bere kutsu didaktikoa baina errotiko aldaketa jasan du proiektu pedagogikoak. Hezkuntza prozesuaren protagonistak aldatu egin dira : aurre-erromantismoak goraipatutako baserritarra bihurtu da irakasle eta euskaldun hiritartu eta ikasia (beraz maila sozial handi samarrekoa) ikasle. Garbi gera dadila, eleberri honen jatorrizko hartzailea ez zela preseski baserritarra, paratestu osoki erdaldunak ongi erakusten duenez. Liburu hau Maisu Juan guztientzat idatzia dago, eta Peru Abarka ez da garai hartako benetako baserritar baten moduan ari, baizik eta baserritargoaz noblezia ilustratuak daukan irudi idealizatu batek egingo lukeen modura. Ez da harritzekoa, hortaz Mogelek ez agertaraztea bere eleberrian nobleziaren figurarik (nobleziak irakasle izaten jarraitzen baitu, oraingoan laborariz mozorroturik bada ere). Ez gara mozorro jokoetatik asko urruntzen, ohartuko denez.

Gorago iradoki bezala, Peru laborariaren mozorropetik hitz egiten duen Mogel ere jauntxoen klasekoa zen eta Herriaren Adiskideetarik bat izan zen. Badakigu, bestalde, Herder nazionalismoaren sortzailearen eragin zuzena jasotako Humboldt filologo alemandarraren informatzaileetako bat izan zela -Astarloarekin batera- azken honek Euskal Herria bisitatu zuenean XVIII. mendearen hondarrean. Badakigu, azkenik, Altuna Portu zalduntxoen taldearen lehen eragileak harreman estua izan zuela primitibo edo "salbaia ona"ren mitoa asmatu zuen Rousseau aurre-erromantiko handiarekin ${ }^{20}$. Rousseauren espezialista euskaldun batek, Xabier Palaciosek, ongi azaldu duenez Rousseauren testuak itzultzen aritzen ziren Zalduntxoak beraien akademian, autore honen obrak inkisizio espainolaren indexean aurkitu arren. Mogelek Rousseau eta Herder testuetatik ezagutzen zituela dudatzeko ez dago apenas arrazoirik. Are gutxiago Peru Abarka irakurri ondoren. Laborariaren ahotan ezarriz zuhurtzia, jakintza eta euskalduntasun jatorraren esentzia, XIX. mende osoa besarkatuko duen iraultza erromantiko-filologikoari nahiz Chahorekin loratzen joango den pentsamendu nazionalistari ateak zabaltzen dizkie Mogelek. Nortasun nazionala da altxor berriaren izena eta hizkuntza nazionalean hobetoen islatzen den altxor horren zaindari nagusia baserritarra da. Tradizioa (erlixioari lotua oraindik Mogelen obran) berreskuratzea, jatortasuna eta primitibotasun ideala berreskuratzearen sinonimo bihurtzen da pentsakera honetan. Eta guzti honen nahigabeko efektua hierarkia sozio-politikoaren deslegitimazioa da zeren bertako nortasun nazional jatorra

20 - PALACIOS, X., Jean Jacques Rousseau-ren Instrucción de un padre a su hijo sobre el modo de conducirse en este mundo-ren edizio kritikoa, Ed. Instituto de Estudios sobre Nacionalismos Comparados, VitoriaGasteiz, 1996. 
oztopatzen duen kultura eta baloreak garai hartako gizartean boterea hartzen hasi den burgesia liberalarena baita. Sozialki eta ekonomikoki indarra galtzen ari den bertako noblezia zaharra baserritargoan aliatu berriak aurkitu nahiean dabilela esan liteke. Hortik ikuspegi ilustratu neoklasiko batetik ikuspegi aurre-erromantiko populista batera igarotzeko beharra ${ }^{21}$. Gudu karlistak ez daude oso urrun jada.•

\section{Bibliografia}

- ALTZIBAR, X., Conde de Peñaflorida-ren El Borracho Burlado-ren edizio kritikoa, Ed. Euskal Parlamentua, Collección Fondo Histórico, Vitoria-Gasteiz, 1991.

- ARISTOTE, (1991) Rhétorique, Paris : Le livre de poche.

- DOMINGUEZ, J., La Música y la Opera en la Historia de Euskalerria, Ed. Diputación Foral de Vizcaya, Bilbao-Bilbo, 1984.

- ECO, U., Lector in fabula, Paris, Livre de Poche (collection Biblio essais), 1985 (itzulpena).

- GENETTE, G., (1997) L'œ uvre de l'art II. La rela tion esthétique, Paris, Seuil.

- GOULEMOT J.-M. et OSTER, D., (1992) Gens de lettres, écrivains et bohèmes, Paris : Minerve.

— GROUT, D.J., "Opéra bouffe et opéra-comique”, in Histoire de la musique 2, Ed. Pléiade, Paris, 1963.

- JAUSS, H.R., Pour une esthétique de la réception littéraire, (1978) : Paris, Gallimard.

- JUARISTI, J., Litera tura va sca, Ed.Taurus, Madrid, 1987.

- KORTAZAR, J., (1990) Litera tura va sca siglo XX, Donostia, Etor.

- LASAGABASTER, J.M., "La literatura vasca entre 1700 y 1876” in Noveno Congreso de Estudios Vascos. Antecedentes próximos de la Sociedad Va sca actual. Siglos XVIII y XIX, Ed.Eusko Ikaskuntza-Sociedad de Estudios Vascos, Bilbo-Bilbao, 1983.

- MICHELENA, L., Historia de la Literatura Vasca, Ed. Erein, San SebastiánDonostia, 1988 (Minotauro, Madrid, lehen argitaralpena 1960-koa da).

- PALACIOS, X., Jean Jacques Rousseau-ren Instrucción de un padre a su hijo sobre el modo de conducirse en este mundo-ren edizio kritikoa, Ed. Instituto de Estudios sobre Nacionalismos Comparados, Vitoria-Gasteiz, 1996.

- PEÑAFLORIDA, Conde de, "Historia de la Real Sociedad Bascongada de Amigos del País, in RIEV (Revista Internacional de Estudios Vascos), Ed. Biblioteca de la Gran Enciclopedia Vasca, Bilbao-Bilbo, 1972 (facsimileko 21. eta 22. liburukiak).

- RODRIGUEZ, F., Fa ustoren Itza la, Donostia, Utriusque Vasconiæ, 2004.

- SAMANIEGO, F.M., "Carta sobre el teatro", in Julián Apraiz, Obras críticas de D.F.M. Sa maniego, Cardenal, 1898, p.81-102.

- URKIZU, P., Historia del tea tro va sco, Ed. Orain, Bilbao-Bilbo, 1996.

21 - Interesgarria da ikustea nola, berrikitan Fito Rodriguezek eleberri batean azaldu duenez (Faustoren Itza la, Donostia : Utriusque Vasconiæ, 2004), Herriaren Adiskideen Elkarte ilustratu eta ustez patriotikoa funtsean espainiar koroak baimendutako eta are bultzaturikofinantzaturiko mugimendua izan zela ; menpekotasun horren adibiderik harrigarriena Elhuyar anaiena delarik, orain frogatua geratu baita beraien esperientzia kimikoak zelataritza industrialaren mailakoak zirela hein batean eta beraien deskubrimenduak espainiar koroaren teknologia militarraren hobekuntzaren mesedetan egin zirela. Badirudi Mogelen garaiean bertako noblezia zaharra ohartzen hasten dela harreman bikoitz horien arriskuetaz. 